\title{
Genome-wide association study for methane emission traits in Danish Holstein cattle
}

\author{
C. I. V. Manzanilla-Pech, ${ }^{1 *} \oplus$ G. F. Difford, ${ }^{2} \odot$ G. Sahana, ${ }^{1} \oplus$ H. Romé, ${ }^{1} \oplus$ P. Løvendahl, ${ }^{1} \oplus$ and J. Lassen ${ }^{3} \oplus$ \\ ${ }^{1}$ Center for Quantitative Genetics and Genomics, Aarhus University, Blichers Alle 20, 8830 Tjele, Denmark \\ ${ }^{2}$ Department of Breeding and Genetics, Nofima AS, PO Box 210, N-1431 Ås, Norway \\ ${ }^{3}$ Viking Genetics, Ebeltoftvej 16, Assentoft, 8960 Randers, Denmark
}

\begin{abstract}
Selecting for lower methane emitting cows requires insight into the most biologically relevant phenotypes for methane emission, which are close to the breeding goal. Several methane phenotypes have been suggested over the last decade. However, the (dis)similarity of their underlying genetic architecture and correlation structures are poorly understood. Therefore, the objective of this study was to test association of SNP and genomic regions through GWAS on $8 \mathrm{CH}_{4}$ emission traits in Danish Holstein cattle. The traits studied were methane concentration (MeC; ppm), methane production (MeP ; g/d), 2 definitions of residual methane (RMETc and RMETp: MeC and MeP regressed on metabolic body weight and energy-corrected milk, respectively), 2 definitions of methane intensity (MeI; MeIc $=\mathrm{MeC} /$ $\mathrm{ECM}$ and $\mathrm{MeIp}=\mathrm{MeP} / \mathrm{ECM}) ; 2$ definitions of methane yield per kilogram of dry matter intake $(\mathrm{MeY} ; \mathrm{MeYc}=$ $\mathrm{MeC} /$ dry matter intake and $\mathrm{MeYp}=\mathrm{MeP} /$ dry matter intake). A total of 1,962 cows with genotypes (Illumina BovineSNP50 Chip or Eurogenomic custom SNP chip) and repeated records of the above-mentioned 8 methane traits were analyzed. Strong associations were found with 3 traits (MeC, $\mathrm{MeP}$, and $\mathrm{MeYc}$ ) on chromosome 13 and with 5 traits (MeC, MeP, MeIp, MeYp, and $\mathrm{MeYc}$ ) on chromosome 26. For MeIc, MeIp, RMETc, $\mathrm{MeYc}$, and MeYp, some suggestive association signals were identified on chromosome 1. Genomic segments of $1 \mathrm{Mbp}(\mathrm{n}=2,525)$ were tested for their association with these traits, which identified between 33 to 54 significantly associated regions. In a pairwise comparison, $\mathrm{MeC}$ and $\mathrm{MeP}$ were the traits that shared the highest number of significant segments (17). The same trend was observed when comparing SNP significantly associated with the traits $\mathrm{MeC}$ and $\mathrm{MeP}$ shared from 23 to $25 \mathrm{SNP}$ (most of which were located in chromosomes
\end{abstract}

Received March 5, 2021.

Accepted October 7, 2021.

*Corresponding author: coralia.manzanilla@qgg.au.dk
11, 13, and 26). Based on our results on GWAS and genetic correlations, we conclude that $\mathrm{MeC}$ is (genetically) more closely linked to $\mathrm{MeP}$ than any of the other methane traits analyzed.

Key words: genome-wide association study, methane yield, methane intensity, residual methane

\section{INTRODUCTION}

Enteric fermentation by ruminants contributes to $44.3 \%$ of the global livestock emissions (FAO, 2018). Western European livestock produces 15\% of the world GHG emissions while concurrently contributing to $25 \%$ of the world's milk production (FAO, 2018). Genetic selection of low methane $\left(\mathrm{CH}_{4}\right)$ emitting cows can be an effective and sustainable approach to reduce GHG production from dairy cattle (Garnsworthy et al., 2012; Lassen and Difford, 2020). Given that genetic progress is cumulative over generations, selecting low $\mathrm{CH}_{4}$ emitting animals could yield significant reductions in emissions within a few generations. However, multiple $\mathrm{CH}_{4}$ phenotypes have been proposed and there is currently a lack of consensus on the optimal $\mathrm{CH}_{4}$ trait for the breeding goal (de Haas et al., 2017; Løvendahl et al., 2018).

The lack of consensus stems from the different combinations of the directly measured methane production in $\mathrm{g} / \mathrm{d}(\mathbf{M e P})$ and other traits such as DMI (which is a substantial driver in variation in $\mathrm{MeP}$ ) as well as BW and ECM, which are energy sinks for DMI (Tempelman et al., 2015). The most prominent combination traits include ratio traits such as methane intensity (MeI; $\mathrm{CH}_{4}$ per kilogram of milk, milk yield, or ECM) and methane yield ( $\mathbf{M e Y} ; \mathrm{CH}_{4}$ per $\mathrm{kg}$ of DMI), as well as residual methane emission traits, which are estimated using multiple linear regression on various combinations of metabolic body weight (MBW), ECM, and DMI (Donoghue et al., 2016; Hayes et al., 2016; Richardson et al., 2021). The residual $\mathrm{CH}_{4}$ traits can be further divided into genetic residual methane and phenotypic residual methane (Manzanilla-Pech et al., 2016; Rich- 
ardson et al., 2021). The purpose of computing different linear combinations is to remove the covariance between $\mathrm{MeP}$ and other traits driving variation in $\mathrm{CH}_{4}$ (DMI, ECM, BW), making $\mathrm{CH}_{4}$ emission statistically independent of these traits.

The need for cost-effective, noninvasive, and largescale phenotyping under commercial conditions has given rise to an additional class of $\mathrm{CH}_{4}$ traits, namely $\mathrm{CH}_{4}$ breath concentration (referred to as $\mathrm{CH}_{4}$ concentration, MeC; Madsen et al., 2010; van Engelen et al., 2015; Difford et al., 2020). The majority of genetic research has been conducted using sniffers installed in automated milking stations (Lassen and Difford, 2020), but also a highly portable handheld laser $\mathrm{CH}_{4}$ detector (Mühlbach et al., 2018). However, to calculate $\mathrm{CH}_{4} \mathrm{~g} / \mathrm{d}$ (referred to as $\mathrm{MeP}$ ) and subsequently the other $\mathrm{CH}_{4}$ traits from $\mathrm{MeC}$, the ratio of recorded $\mathrm{CH}_{4}: \mathrm{CO}_{2}$ gas concentrations is multiplied by predicted $\mathrm{CO}_{2}$ tracer gas using ECM and BW (Madsen et al., 2010). This could lead to an artificially induced covariance structure between traits resulting in high correlations with ECM and BW, and potentially with DMI as well. Somewhat counter-intuitively, researchers are then required to remove the covariance with ECM and BW through calculating the ratio or residual traits discussed above. For this reason, some authors have used MeC directly in genetic parameter estimations (Difford et al., 2020; Manzanilla-Pech et al., 2020).

Investigations into the underlying genomic architecture of different $\mathrm{CH}_{4}$ traits can generate knowledge of the origin of genetic variation in different $\mathrm{CH}_{4}$ phenotypes. This will indicate the genetic closeness of different $\mathrm{CH}_{4}$ phenotypes. Only few authors (Manzanilla-Pech et al., 2016; Pszczola et al., 2018; Calderon-Chagoya et al., 2019) have investigated the genomic architecture behind $\mathrm{CH}_{4}$ traits. However, due to the inherently small data sets and populations with $\mathrm{CH}_{4}$ records available in the world, only a few studies have performed GWAS with a limited number of animals $(\mathrm{n}<300$; Manzanilla-Pech et al., 2016; Pszczola et al., 2018; Calderon-Chagoya et al., 2019). Therefore, the objective of this study was to test association of SNP and genomic regions through GWAS on $8 \mathrm{CH}_{4}$ emission traits in a larger data set with Danish Holstein cattle. The traits studied were $\mathrm{MeC}\left(\mathrm{CH}_{4}\right.$ concentration), $\mathrm{MeP}\left(\mathrm{CH}_{4}\right.$ production; g/d), 2 definitions of residual $\mathrm{CH}_{4}$ (RMETc and RMETp: $\mathrm{MeC}$ and $\mathrm{MeP}$ regressed on $\mathrm{MBW}$ and $\mathrm{ECM}$, respectively), 2 definitions of $\mathrm{CH}_{4}$ intensity $(\mathrm{MeIc}=\mathrm{MeC} /$ $\mathrm{ECM}$ and $\mathrm{MeIp}=\mathrm{MeP} / \mathrm{ECM}) ; 2$ definitions of $\mathrm{CH}_{4}$ yield per $\mathrm{kg}$ DMI $(\mathrm{MeYc}=\mathrm{MeC} / \mathrm{DMI}$ and $\mathrm{MeYp}=$ $\mathrm{MeP} / \mathrm{DMI})$. In this study, we used both $\mathrm{MeC}$ and $\mathrm{MeP}$ to calculate different definitions of $\mathrm{MeI}, \mathrm{MeY}$, and residual $\mathrm{CH}_{4}$, respectively.

\section{MATERIALS AND METHODS}

\section{Data Collection and Traits}

A total of 1,962 Danish Holstein cows with weekly records on $\mathrm{CH}_{4}$ breath concentration $(7,227$ records), BW (7,295 records), milk yield (7,311 records), and DMI (4,785 records) were available from the Danish Cattle Research Center (DCRC, Tjele, Denmark) and 10 commercial farms in Denmark. Data were collected between 2011 and 2016, and were previously described by Zetouni et al. (2018), Difford et al. (2020), and Manzanilla-Pech et al. (2020). Methane concentration was measured by 2 sniffer methods (Garnsworthy et al., 2012; Lassen et al., 2012): the nondispersive infrared $\mathrm{CH}_{4}$ sensor (Guardian NG, Edinburgh Instruments Ltd.) in the research farms and some commercial farms and the portable Fourier transform infrared Gasmet DX-4000 (Gasmet; Gasmet Technologies Oy) in the commercial farms. Both methodologies were described and compared previously (Difford et al., 2016). Methane concentration $\left(\mathrm{CH}_{4}\right.$ in ppm, referred to as $\left.\mathrm{MeC}\right)$ was not normally distributed, thus, a natural logarithm transformation was applied, and finally it was multiplied by 100 to avoid problems with the scale of the other traits. Data from research and commercial farms were filtered to only include weekly averages where a maximum of $3 \mathrm{~d}$ was allowed to be missing within a week, and a cow had a minimum of 3 weekly measurements. Methane production $\left(\mathrm{CH}_{4}\right.$ in $\mathrm{g} / \mathrm{d}$, referred to as $\mathbf{M e P}$ ) was calculated as follows: first, $\mathbf{C H}_{4}$ was computed in liters using the formula of Madsen et al. (2010) based on heat-producing units (HPU):

$$
\mathrm{CH}_{4}(\mathrm{~L} / \mathrm{d})=\left(\mathrm{CH}_{4} / \mathrm{CO}_{2}\right) \times 180 \times 24 \times \mathrm{HPU},
$$

where

$$
\begin{aligned}
\mathrm{HPU}=5.6 \mathrm{MBW}+22 \mathrm{ECM}+1.6 \times 10^{-5} \\
\times \text { days carried calf. }
\end{aligned}
$$

Second, $\mathrm{CH}_{4}$ was converted in $\mathrm{L} / \mathrm{d}$ to $\mathrm{g} / \mathrm{d}$ using the formula:

$$
\mathrm{MeP}=\mathrm{CH}_{4} \mathrm{~g} / \mathrm{d}=\text { density } \times \mathrm{CH}_{4}(\mathrm{~L} / \mathrm{d}),
$$

where the density of $\mathrm{CH}_{4}$ at $20^{\circ} \mathrm{C}=0.668 \mathrm{~g} / \mathrm{L}$.

Cows were located at the DCRC (Foulum, Denmark) and were fed automatically with feeders (Insentec, RIC system) as reported in Li et al. (2017). Cows at DCRC were part of several nutritional experiments and diets included primarily rolled barley, corn silage, grass clover silage, rapeseed meal, and soybean meal. 
The DCRC barn is a loose housing system with access to automatic milking systems (AMS; DeLaval International AB). Milk composition was determined using infrared technology at Eurofins using CombiFoss equipment (Foss). The AMS was fitted with a weighing platform (Danvaegt) that recorded BW at each milking from which weekly averages were calculated (full description can be found in Li et al., 2017). For the 10 commercial farms, weekly average milk yield and milk components were available from the national recording scheme (RYK, Skejby, Denmark). Body weight in commercial farms was measured with weighing scales in the AMS as well. Metabolic BW was defined as BW ${ }^{0.75}$.

Energy-corrected milk was calculated using the following formula (Sjaunja et al., 1990):

$$
\begin{aligned}
\operatorname{ECM}(\mathrm{kg})= & 0.25 \text { milk }(\mathrm{kg})+12.2 \text { fat }(\mathrm{kg}) \\
& +7.7 \text { protein }(\mathrm{kg}) .
\end{aligned}
$$

After calculating MeP, residual methane (RMETp) was the residual of the partial regression of $\mathrm{MeP}$ on MBW and ECM along with fixed effects described later in model [5]. Methane intensity [MeIp; MeP (g/d)/ ECM $(\mathrm{kg} / \mathrm{d})$ ] was calculated using MeP divided by ECM, $\mathrm{CH}_{4}$ yield [MeYp; MeP (g/d)/DMI (kg/d)] was calculated using MeP divided by DMI. With the purpose of testing the use of $\mathrm{MeC}$ instead MeP, RMETc (residual of the partial regression of $\mathrm{MeC}$ on $\mathrm{MBW}$ and ECM), MeIc (MeC divided by ECM), MeYc (MeC divided by DMI) were calculated as well. The reasoning behind this is that for MeIp, ECM, and BW are needed to calculate $\mathrm{MeP}$, whereas only ECM is used to calculate $\mathrm{CH}_{4}$ intensity when using $\mathrm{MeC}$ (MeIc), leaving a portion of $\mathrm{BW}$ in the trait. Unlike other $\mathrm{CH}_{4}$ traits, residual methane emission traits are independent of the traits used as regressors (in this case both ECM and $\mathrm{BW}$ ). Both $\mathrm{CH}_{4}$ yield traits ( $\mathrm{MeYc}$ and $\mathrm{MeYp}$ ) resulted in a reduced number of animals and observa- tions (Table 1) as commercial herds do not have DMI records available.

\section{Genotypes}

Two sets of genotypes were available; 1,747 cows were genotyped with BovineSNP50 BeadChip (Illumina), 466 cows were genotyped with Eurogenomics custom SNP chip (LD chip; Boichard et al., 2018), and 74 cows were genotyped with both SNP chips. The genotypes were edited for quality control with the PLINK software (Purcell et al., 2007). Quality control included a minimum of 0.02 for minor allele frequency, a maximum of $10 \%$ genotypes missing per SNP, a maximum of $15 \%$ genotypes missing per animal, and Hardy-Weinberg disequilibrium $(P=0.001)$. In addition, 50K SNP genotypes were kept when an animal was genotyped with both LD and 50K SNP chips. Furthermore, SNP located on sex chromosomes, unmapped SNP, and SNP with duplicate or uncertain positions were deleted. Posteriorly, the LD chip genotypes were imputed to $50 \mathrm{~K}$ with the software FImpute (Sargolzaei et al., 2014). After editing and removing duplicates, 1,962 cows (663 cows from DCRC and 1,299 cows on 10 commercial farms) with 38,253 SNP remained.

\section{Variance Component Estimation (Genomic Heritabilities and Genomic Correlations)}

Variance components for the 8 traits were estimated using the single trait model with AI-REML algorithm in DMU software (Version 6, Release 5.4; Madsen and Jensen, 2014) using a genomic relationship matrix (GRM) with all genotypes. Genetic correlations for the 4 pair traits were estimated through bivariate analyses. The model for the univariate and bivariate analyses was defined as follows:

$$
\mathbf{y}=\mathbf{X b}+\mathbf{Z}_{1} \mathbf{a}+\mathbf{Z}_{2} \mathbf{c}+\mathbf{e}
$$

Table 1. Descriptive statistics for 8 methane traits ${ }^{1}$

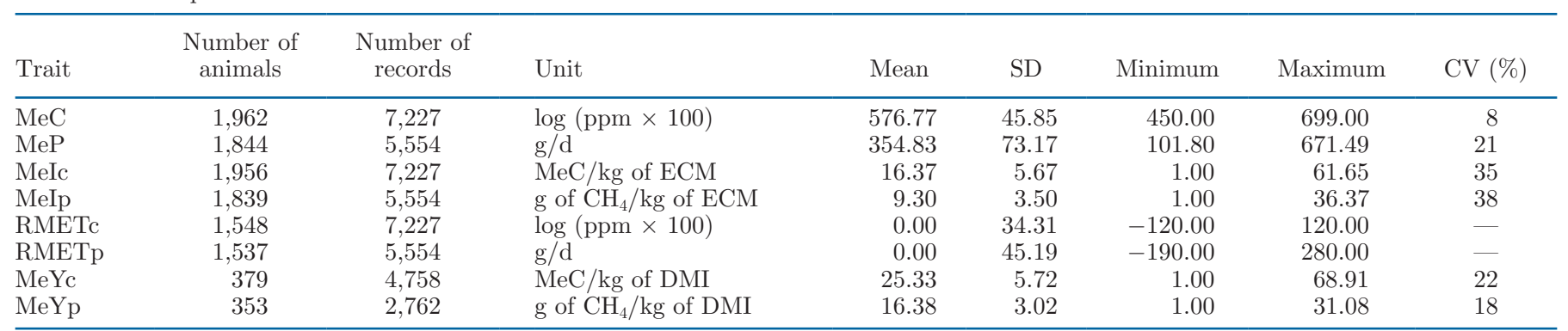

${ }^{1} \mathrm{MeC}=$ methane concentration; $\mathrm{MeP}=$ methane production; MeIc = methane intensity calculated using MeC; MeIp = methane intensity calculated using MeP; RMETc = residual methane on metabolic BW and ECM using MeC; RMETp = residual methane on metabolic BW and ECM using MeP; MeYc = methane yield calculated using MeC; MeYp = methane yield using MeC. 
where $\mathbf{y}$ is the vector of phenotypes; $\mathbf{b}$ represents the vector of fixed effects (herd-trial-year-season, lactation week modeled with the Wilmink function, type of sniffer, and parity number as 1,2 , and $\geq 3$ ), for all traits except the residual traits (RMETc and RMETp only have SNP as a fixed effect as they have been corrected before for the other effects), $\mathbf{X}$ is the incidence matrix relating observations with fixed effects; $\mathbf{a}$ is the vector of direct additive genetic effects; $\mathbf{Z}_{1}$ is the incidence matrix relating observations with random genetic effects; $\mathbf{c}$ is the vector of permanent environmental effects; $\mathbf{Z}_{2}$ is the incidence matrix relating observations with random permanent environmental effect; and $\mathbf{e}$ is the vector of residual effects. Distributions of the random effects were $\operatorname{var}(\mathbf{a})=\mathbf{G} \sigma_{a}^{2}$, where $\mathbf{G}$ is the genomic relationship matrix and $\sigma_{a}^{2}$ is the additive genomic variance, $\operatorname{var}(\mathbf{c})=\mathbf{I} \sigma_{c}^{2}$, where $\mathbf{I}$ is identity matrix of order equal to the number of individuals with records and $\sigma_{c}^{2}$ is the permanent environmental variance, and $\operatorname{var}(\mathbf{e})=\mathbf{I} \sigma_{e}^{2}$, where $\mathbf{I}$ is an identity matrix of an order equal to the number of observations and $\sigma_{e}^{2}$ is the residual variance.

\section{GWAS}

Genome-wide association studies were performed using a single SNP regression analyses with DMU software (Version 6, Release 5.4; Madsen and Jensen, 2014) to determine the association of each SNP with the 8 analyzed traits (MeC, MeP, RMETc, RMETp, MeIc, MeIp, MeYc, MeYp,) using a linear mixed model and repeated records. The following univariate model was used per SNP for each of the 8 traits:

$$
\mathbf{y}=\mathbf{X b}+\beta_{1} \mathbf{S N P}_{\mathbf{i}}+\mathbf{Z}_{\mathbf{1}} \mathbf{a}_{\left(\text {without }_{\mathbf{j}}\right)}+\mathbf{Z}_{\mathbf{2}} \mathbf{c}+\mathbf{e}
$$

where $\mathbf{y}$ is the vector of phenotypes; $\mathbf{b}$ represents the vector of fixed effects (same as in [5]), $\mathbf{X}$ is the incidence matrix relating observations with fixed effects; $\beta_{1}$ is the effect of $\mathrm{SNP}_{\mathrm{i}}$ of the individual examined, $\mathbf{S N P}_{\mathrm{i}}$ is the vector of SNP for the ith SNP genotype indicator variable coded as 0,1 , or 2 for an individual; $\mathbf{a}_{\left(\text {without }_{\mathbf{j}} \text { ) }\right.}$ is the vector of direct additive genetic effects due to all the SNP except those on chromosome $\mathrm{j}$ where $\mathrm{SNP}_{\mathrm{i}}$ is located; $\mathbf{Z}_{1}$ is the incidence matrix relating observations with random genetic effects; $\mathbf{c}$ is the vector of permanent environmental effects; $\mathbf{Z}_{\mathbf{2}}$ is the incidence matrix relating observations with random permanent environmental effect; and $\mathbf{e}$ is the vector of residual effects. Distributions of the random effects were $\operatorname{var}(\mathbf{a})=$ $\mathbf{G} \sigma_{a}^{2}$, where $\mathbf{G}$ is the genomic relationship matrix constructed leaving out chromosome $\mathrm{j}$ and $\sigma_{a}^{2}$ is the addi- tive genomic variance, $\operatorname{var}(\mathbf{c})=\mathbf{I} \sigma_{c}^{2}$, where $\mathbf{I}$ is identity matrix of order equal to the number of individuals with records and $\sigma_{c}^{2}$ is the permanent environmental variance, and $\operatorname{var}(\mathbf{e})=\mathbf{I} \sigma_{e}^{2}$, where $\mathbf{I}$ is an identity matrix of an order equal to the number of observations and $\sigma_{e}^{2}$ is the residual variance. After SNP effects were estimated with DMU, $P$-values were calculated from a $t$-value $(\boldsymbol{t}$, from $t$ distribution), which is the coefficient $\beta_{1}$ divided by its standard error $\left(t=\beta_{1} / \mathrm{SE}\right)$ with $\mathrm{n}-2$ degrees of freedom, where $\mathrm{n}$ is the sample size.

\section{Segments (Base Pair Windows) and SNP Comparison Between Traits}

Using the GWAS results, a total of 2,525 nonoverlapping windows of $1 \mathrm{Mbp}$ ( 1 million bp) across the 29 chromosomes were created, these segments contained on average 15 SNP. The aim of these windows was to identify regions significantly associated with each trait and posteriorly to determine regions in common across traits using a $\chi^{2}$ pairwise test. Given that there could be some significant SNP in the same region without being exactly in the same bp position (same SNP; Khansefid et al., 2014). Second, these windows were created to determine significant SNP associated with more than one trait, pairwise comparisons of the data sets of significant SNP associated with the 8 different traits were used with the same procedure. Statistical significance of each SNP was determined using a $\chi^{2}$ pairwise test to evaluate if the same SNP were significant in both traits rather than the expected by chance (Khansefid et al., 2014). Finally, the segments were compared with the cattle QTL database (Hu et al., 2013). The current release of the Cattle QTL database contains 160,659 QTL/associations from 1,030 publications, with 675 different traits, related to feed, production, maintenance and health $\left(\mathrm{CH}_{4}\right.$ traits are not included yet).

\section{RESULTS AND DISCUSSION}

Descriptive statistics for $\mathrm{CH}_{4}$ traits are presented in Table 1. The estimates of the averages for $\mathrm{MeP}$ and MeIp are in agreement with Lassen and Løvendahl (2016) of $315 \mathrm{~g} / \mathrm{d}$ and $8.61 \mathrm{~g} / \mathrm{L}$ ECM using a subset of the data set in this study. However, Pszczola et al. (2017) reported much lower average $(279 \mathrm{~g} / \mathrm{d})$ for $\mathrm{MeP}$ (calculated similarly as this study) in Polish Holstein cows. Oppositely, Richardson et al. (2021) reported greater averages, $469 \mathrm{~g} / \mathrm{d}$ for MeP, $18.15 \mathrm{~g} / \mathrm{kg}$ ECM for MeI, and $19 \mathrm{~g} / \mathrm{kg}$ DMI for MeY, in grazing Australian Holstein cows with the $\mathrm{SF}_{6}$ method. It is unclear how much the method of measurement for $\mathrm{CH}_{4}$ or the diet or the combination of both could affect the average 
MeP. For example, Garnsworthy et al. (2019) observed that $\mathrm{MeP}$ from the $\mathrm{SF}_{6}$ method was consistently greater than all other methods (sniffers, laser, chambers, GreenFeed), but this method is also primarily used on grazing animals, which are expected to have greater roughage to concentrate intake ratio and thus greater $\mathrm{CH}_{4}$. Finally, the average for $\mathrm{MeC}$ (5.6; without multiplication of 100) was similar to values by Difford et al. (2020) with a subset of the data set used in this study.

\section{Estimated Genetic Parameters}

Estimated heritabilities (Table 2) for all traits ranged between 0.09 (MeYc) and 0.21 (RMETc), being 0.14 for $\mathrm{MeC}$ and 0.15 for MeP. Lassen and Løvendahl (2016) have reported a heritability of 0.21 for both MeP and MeI in Danish Holstein cows from multiple commercial herds, using a single average weekly record per cow (average $\mathrm{MeP}$ and $\mathrm{MeI}$ distributed over the lactation). Difford et al. (2020) reported heritabilities of 0.16 for $\mathrm{MeC}$ in Dutch Holstein cows and 0.26 for $\mathrm{MeC}$ in Danish Holstein cows mainly using mostly longitudinal data from a single research farm in each country. It appears that heritability estimates tend to be greater in research herds with continuous recording than in commercial herds with recording from short intervals. The heritability in the current study is based on data from both commercial and research herds and thus slightly lower heritability may reflect the greater number of records from commercial herds. Similar heritability for MeP (0.16) was reported by Richardson et al. (2021) in Australian Holstein cows, and was greater for $\mathrm{MeY}$ (0.23) and MeI (0.33) using $\mathrm{SF}_{6}$. Furthermore, Pszczola et al. (2017) reported heritabilities for daily MeP, obtained via sniffers, ranging from 0.23 to 0.30 across lactation in 2 herds. Heritability estimates for residual traits are not directly comparable as trait definition varied widely across studies. In Australian Holstein cattle, Richardson et al. (2021) reported heritabilities between 0.11 to 0.21 for 9 trait definitions of residual methane involving genetic and phenotypic regression of $\mathrm{MeP}$ on a combination of DMI and ECM corrected for DIM, parity, and experimental batch using phenotypes or direct genomic values. Furthermore, most of the above-mentioned studies, except Richardson et al. (2021), used pedigree relationships matrices instead genomic relationship matrices to estimate the heritabilities, which could affect the size of the heritability estimates presented here.

Genetic correlations between traits are presented in Table 2. Genetic correlations between all traits were estimated via bivariate analyses, but did not converge for some of the combinations (partially due to the few animals and records available for MeY traits). For this reason, only the genetic correlations between similar pair traits were reported, all of which did converge. The genetic correlation between $\mathrm{MeC}$ and $\mathrm{MeP}$ was 0.91 ( $\mathrm{SE}=0.07)$ in this study. Genetic correlations between other trait pairs were $0.46(\mathrm{SE}=0.19)$ for MeIc and MeIp, $0.78(\mathrm{SE}=0.14)$ for MeYc and MeYp, and 0.65 ( $\mathrm{SE}=0.23)$ for RMETc and RMETp. The genetic correlation between $\mathrm{MeC}$ and $\mathrm{MeP}$ showed a closer similarity between these 2 traits than between the other trait pairs. This does not come as a surprise; a positive correlation between these traits was expected, as $\mathrm{MeC}$ is an important part for the calculation of $\mathrm{MeP}$ (as the ratio between $\mathrm{CH}_{4}$ and $\mathrm{CO}_{2}$ concentrations is used in the calculation of formula [1]). Correlations between other trait pairs were also expected to be lower as they involve traits such as ECM, BW, and DMI, all of them with larger genetic variance than $\mathrm{CH}_{4}$ itself. Genetic correlations between these trait pairs have not been reported before, as $\mathrm{MeC}$ is not a trait widely studied.

\section{GWAS Results}

Genome-wide association plots $\left[-\log _{10}(P)\right]$ of MeP, MeC, MeIc, MeIp, RMETc, RMETp, MeYc, and MeYp are presented in Figure 1. Quantile-quantile plots for MeP, MeC, MeIc, MeIp, RMETc, RMETp, MeYc, and MeYp are presented as Supplemental Figure S1 (https: //dataverse.harvard.edu/dataverse/suplementalS1). There was no common pattern between the Manhattan plots of the $8 \mathrm{CH}_{4}$ traits, meaning that there are no chromosomes with significant SNP presented for all traits. Strong associations were established on chromosome 13 in 3 traits $(\mathrm{MeC}, \mathrm{MeP}$, and $\mathrm{MeYc})$ and on chromosome 26 in 5 traits (MeC, MeP, MeIp, MeYp, and MeYc). However, for MeIc, MeIp, RMETc, MeYc, and MeYp, some suggestive association signals were identified on chromosome 1. Additionally, RMETc and MeIc

Table 2. Estimated heritabilities $\left(h^{2}\right)$ of 8 methane traits and genetic correlations ( $\mathrm{r}_{\mathrm{g} ;}$ SE in parentheses) between similar pair traits ${ }^{1}$

\begin{tabular}{lcc}
\hline Trait & $\mathrm{h}^{2}$ & $\mathrm{r}_{\mathrm{g}}$ \\
\hline MeP & $0.12(0.03)$ & $0.91(0.07)$ \\
MeC & $0.15(0.03)$ & $0.46(0.19)$ \\
MeIc & $0.04(0.03)$ & \\
MeIp & $0.04(0.03)$ & $0.65(0.23)$ \\
RMETc & $0.11(0.03)$ & $0.78(0.14)$ \\
RMETp & $0.21(0.03)$ & \\
MeYc & $0.09(0.04)$ & \\
MeYp & $0.14(0.04)$ & \\
\hline
\end{tabular}

${ }^{1} \mathrm{MeC}=$ methane concentration; $\mathrm{MeP}=$ methane production; MeIc = methane intensity calculated using $\mathrm{MeC}$; MeIp = methane intensity calculated using MeP; RMETc = residual methane on metabolic BW and ECM using MeC; RMETp = residual methane on metabolic BW and ECM using $\mathrm{MeP} ; \mathrm{MeYc}=$ methane yield calculated using $\mathrm{MeC}$; $\mathrm{MeYp}=$ methane yield using MeC. 
showed associations on chromosomes 2 and 4. Similarly, Pszczola et al. (2018) reported strong associations between $\mathrm{MeP}$ (calculated from $\mathrm{MeC}$ ) and SNP located on chromosomes 1, 4, 9, 13, and 25 using a Bayesian approach in 287 Holstein cows in Poland. Likewise, Calderon-Chagoya et al. (2019) reported associations between MeP (calculated from $\mathrm{MeC}$ ) and chromosomes 1, 3, 13, and 20 in 280 dairy crossbred-dual purpose Mexican cows. Moreover, Manzanilla-Pech et al. (2016) reported strong associations on chromosomes 3, 6, and 13 for $\mathrm{MeP}, \mathrm{MeY}$, and $\mathrm{MeI}$ in Holstein cows in Australia recorded using $\mathrm{SF}_{6}$. Nevertheless, all those studies had relatively small populations ( $<300$ cows). Furthermore, van Engelen (2018) studied approximately 1,700 Dutch Holstein cows and reported significant associations on chromosome 14 for $\mathrm{MeP}$ and $\mathrm{MeY}$ predicted from milk mid-infrared spectra (MIR), and on chromosomes 14 and 19 for 2 definitions of $\mathrm{MeP}$ predicted from milk fatty acids. However, they did not find any significant association for MeI (predicted from MIR). In summary, there appears to be a reliable association on chromosome 13 for MeP based on the results of previous studies in several populations of Holstein in different countries (Manzanilla-Pech et al., 2016; Pszczola et al., 2018; Calderon-Chagoya et al., 2019). In the present study, this association was also present for $\mathrm{MeC}$, as expected because $\mathrm{MeC}$ is used in the calculation of $\mathrm{MeP}$ (as showed in [1]). The GWAS for $\mathrm{MeC}$ or any other trait calculated with $\mathrm{MeC}$ have not been reported before, as $\mathrm{MeC}$ is a relatively understudied trait. However, one of the aims of this paper was to provide some insight about the genetic architecture of $\mathrm{MeC}$ and other $\mathrm{CH}_{4}$ traits calculated using $\mathrm{MeC}$, in comparison to the traditional $\mathrm{CH}_{4}$ traits (MeP, MeI, and $\mathrm{MeY}$ ). Adjusted $\mathrm{CH}_{4}$ traits had weaker associations across all the chromosomes compared with $\mathrm{MeC}$ and $\mathrm{MeP}$, except for MeYc and MeYp. Finally, adjusted traits using MeP (MeIp, RMETp, and MeYp,) had fewer SNP associated across chromosomes compared with adjusted traits using $\mathrm{MeC}$ (MeIc, RMETc, and MeYc). Our hypothesis is that adding $\mathrm{ECM}$ and $\mathrm{BW}$ to calculate $\mathrm{MeP}$ and subsequently correcting for ECM and BW could be causing the loss of some association signals, meaning that these traits have been statistically overcorrected. This is especially clear in RMETp, which shows practically no significant associations between the SNP and the trait. In Figure $1, \mathrm{MeY}$ traits showed very strong association signals for chromosome $1\left(P=8.22 \times 10^{-12} ; \mathrm{MeYp}\right)$ and $24(P$ $\left.=1.59 \times 10^{-14} ; \mathrm{MeYc}\right)$; however, these results should be taken carefully, as the number of animals/genotypes for these traits is much lower than for the other traits (Table 1). According to Gebreyesus et al. (2019) who performed a power detection test on a several Holstein populations, as a function of sample size and proportion of explained variance by a QTL, a population of 2,880 animals could have a detection power of 0.97 , whereas a population of 1,566 animals could have a detection power of 0.57 and a population of 614 animals only 0.05 to detect QTL explaining 5\% of the genetic variance. Based on these results (Gebreyesus et al., 2019), we can infer that we have much more power of QTL detection for MeC $(\mathrm{n}=1962)$ and $\mathrm{MeP}(\mathrm{n}=1,844)$ than for the other traits, especially for MeYc $(\mathrm{n}=379)$ and MeYp $(\mathrm{n}=353)$. Therefore, ideally, we would need around 3,000 animals per trait to have an optimal power of detection for QTL explaining at least $5 \%$ of the genetic variance.

\section{Significant Segments and SNP Within and Between Traits}

In Table 3 , significant $(P<0.001)$ segments of 1 Mbp associated with and between all traits $(\mathrm{MeC}$, MeP, MeIc, MeIp, RMETc, RMETp, MeYc, and MeYp) are presented. The total number of segments across the chromosomes was 2,525, and significant segments across traits ranged from $33(\mathrm{MeYp})$ to 54 (MeP, MeIc). Less significant segments were found for traits that used MeP instead MeC, except for the residual traits. The highest number of significant segments in common between traits was 17 between $\mathrm{MeC}$ and $\mathrm{MeP}$. The number of significant segments in common between pair traits with similar definitions varied; for instance, the intensity ratio traits (MeIc and MeIp) shared 4 segments, whereas residual traits (RMETc and RMETp) and the yield ratio traits (MeYc and MeYp) shared one segment per pair. Furthermore, significant SNP $(P<$ $0.001)$ associated with each of the 8 traits and between traits (using a chi-squared test) are presented in Table 4. The number of significant SNP per trait varied from 36 (RMETc) to 71 (MeYc). Significant SNP in common from a chi-squared pairwise comparison showed that 25 (out of the 66) significant SNP for MeP were also significant for $\mathrm{MeC}$, and 23 (out of the 42) significant SNP for MeC were also significant for MeP. However, MeIc and MeIp shared many fewer SNP (5 from 65 SNP and 4 from 45 SNP). In Table 5, significant SNP associated with 2 traits, with their chromosomal locations, are presented. As we have seen in previous tables, the pair of traits sharing most of the significant SNP were $\mathrm{MeC}$ and $\mathrm{MeP}$, especially on chromosomes 11, 13, and 26. Another pair of traits that shared significant SNP was MeIc and MeIp on chromosomes 4 and 6 . van Engelen (2018) reported strong associations for MeY predicted both from milk MIR and milk fatty acids on chromosome 14, and the SNP were identified as the ones coding for diacylglycerol O-acyltransferase 1 (DGAT1). However, it is hard to disentangle if this 
strong signal could be due to use of milk mid-infrared spectra to predict MeI or if the addition of fat- and protein-corrected milk (FPCM) as the denominator $(\mathrm{MeI}=\mathrm{MeP} / \mathrm{FPCM})$ could have influenced this result. In more detail, Pszczola et al. (2018) reported 16 significant SNP detected for MeP on 6 different chromosomes $(1,4,9,13,20$, and 25) and their respective candidate QTL regions. In this study, we identified 2 significant SNP in common with that study: one on chromosome 1 significantly associated $(P=0.004)$ with MeIp (BTA-89820-nors, 46,321,775 bp), and the other on chromosome 4 associated $(P=0.003)$ with $\mathrm{MeYc}$ (Hapmap39581-BTA-70101, 9203380 bp). According to Pszczola et al. (2018), the SNP on chromosome 1 is associated with 12 candidate genes, and the SNP on chromosome 4 is associated with 14 candidate genes.

\section{Overlap with Cattle QTL Database}

Although QTL for $\mathrm{CH}_{4}$ traits are not in the cattle QTL database, other economically important and $\mathrm{CH}_{4^{-}}$ related traits, including production, health, and feedmaintenance traits, are in this database. Some QTL associated with milk production, feed efficiency, weight, and conformation traits in the cattle QTL database overlap with the significant association segments for $\mathrm{CH}_{4}$ traits identified in this study. In Table 6 , we present a summary of QTL per chromosome reported for
$\mathrm{MeC}$

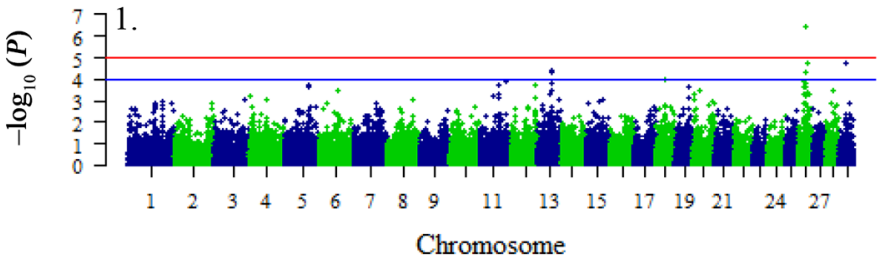

MeIc

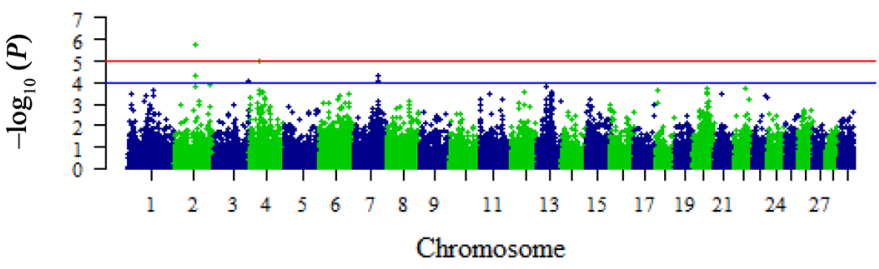

RMETc

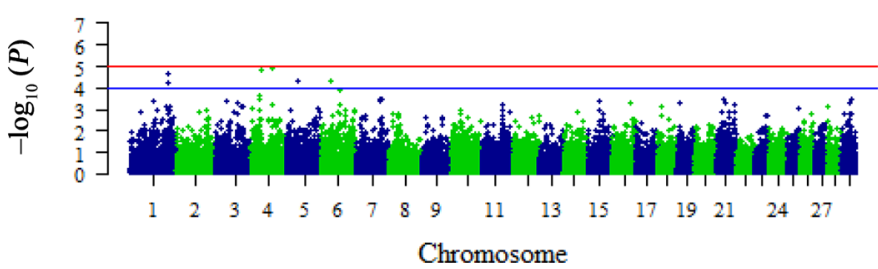

MeYc

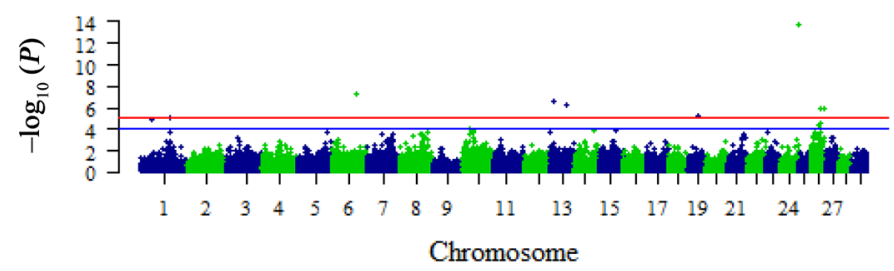

MeP

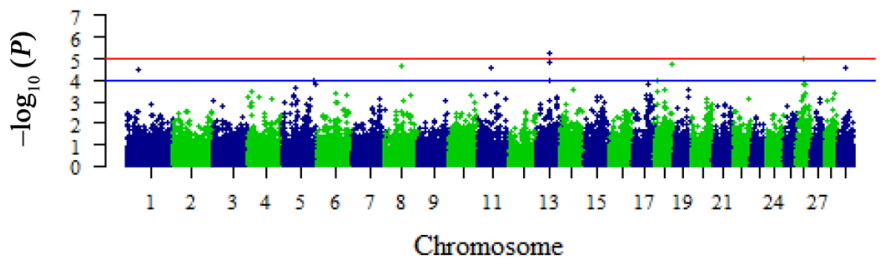

MeIp

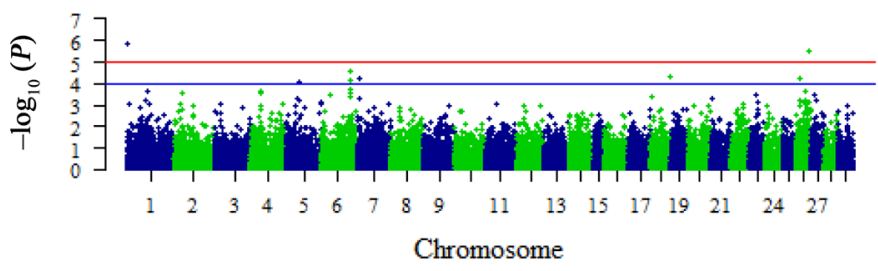

RMETp

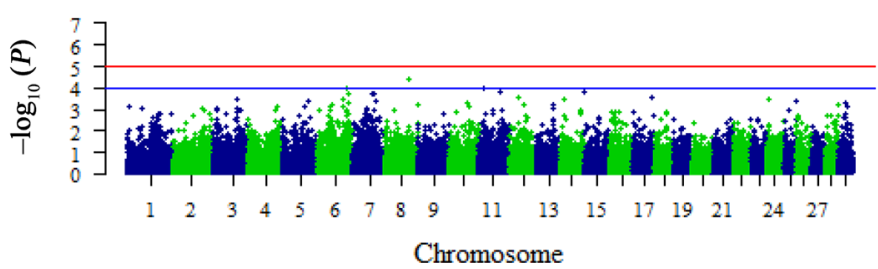

$\mathrm{MeY} \mathbf{p}$

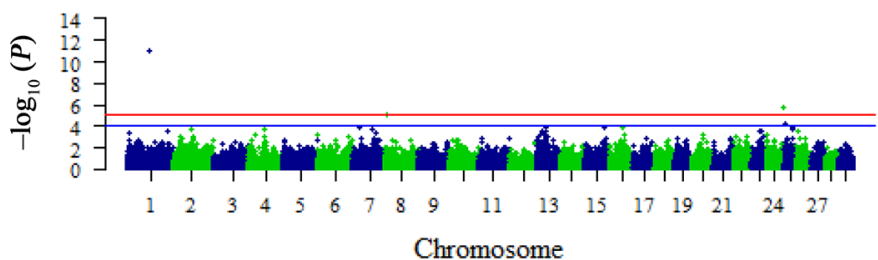

Figure 1. Genome-wide association plots $\left[-\log _{10}(P)\right]$ of methane concentration $(\mathrm{MeC})$, methane production $(\mathrm{MeP})$, methane intensity based on MeC (MeIc), methane intensity based on MeP (MeIp), residual methane based on MeC (RMETc), residual methane based on MeP (RMETp), methane yield based on $\mathrm{MeP}(\mathrm{MeYc})$, and methane yield based on $\mathrm{MeP}(\mathrm{MeYp})$. The genome-wide significance level (lower line) is set at $10 \times$ $10^{-5}$ and is plotted as the blue line. The red line represents the threshold for GWAS significance (upper line) after a Bonferroni correction (10 $\left.\times 10^{-6}\right)$. 
Table 3. Segments significantly $(P<0.001)$ associated with each trait (diagonal, bold) and each pair of traits (below diagonal)

\begin{tabular}{lrrrrrrrr}
\hline Trait $^{1}$ & MeC & MeP & MeIc & MeIp & RMETc & RMETp & MeYc & MeYp \\
\hline MeC & $\mathbf{3 4}$ & & & & & & & \\
MeP & 17 & $\mathbf{5 4}$ & & & & & & \\
MeIc & 1 & 1 & $\mathbf{5 4}$ & & & & & \\
MeIp & 1 & 2 & 4 & $\mathbf{3 7}$ & & & & \\
RMETc & 0 & 0 & 4 & 0 & $\mathbf{3 5}$ & & \\
RMETp & 0 & 0 & 1 & 0 & 1 & 0 & $\mathbf{5 2}$ & \\
MeYc & 5 & 3 & 2 & 5 & 3 & 1 & 1 & $\mathbf{3 3}$ \\
MeYp & 1 & 0 & 0 & 1 & 1 & 1 & \\
\hline
\end{tabular}

${ }^{1} \mathrm{MeC}=$ methane concentration; $\mathrm{MeP}=$ methane production; MeIc = methane intensity calculated using MeC; MeIp = methane intensity calculated using MeP; RMETc $=$ residual methane on metabolic BW and ECM using MeC; RMETp = residual methane on metabolic BW and ECM using MeP; MeYc = methane yield calculated using $\mathrm{MeC} ; \mathrm{MeYp}=$ methane yield using MeC. Total number of segments = 2,525.

Bos taurus associated with significant $(P<0.001)$ segments for $\mathrm{MeC}$, alone or in combination with other $\mathrm{CH}_{4}$ traits. $\mathrm{MeC}$ was chosen because it does not have any artificially induced dependency with ECM and BW, as opposed to $\mathrm{MeP}$ that requires $\mathrm{ECM}$ and $\mathrm{BW}$ for its calculation. Chromosomes 11, 13, and 26 had the most overlapping associations with QTL reported in the database. Among the representative traits associated with these reported QTL (https://www.animalgenome.org/ cgi-bin/QTLdb/index) are fat, protein, and lactose (in percentage and content), milk production, lifetime milk production, DMI, residual feed intake, BW, and several conformation traits highly correlated with weight (stature, chest width, body depth, dairy form, and strength; Manzanilla-Pech et al., 2016). Thirty-one QTL (from 15 chromosomes) were reported to have overlapping regions with the significant regions detected for $\mathrm{MeC}$; 30 of those are associated with milk production traits, 18 with weight, 11 with conformation, and 7 with feed efficiency. Despite the scarcely available literature comparing genomic regions and QTL for important traits in cows, the genetic correlations between $\mathrm{CH}_{4}$ traits and production (Breider et al., 2018; Difford et al., 2020), feed efficiency (Difford et al., 2020; Richardson et al.,
2021), weight, and conformation traits (Breider et al., 2018; Zetouni et al., 2018) are well documented. Thus, associations between $\mathrm{CH}_{4}$ traits and QTL reported for those traits are expected. Moreover, Pszczola et al. (2018) reported genomic regions controlling $\mathrm{CH}_{4}$ associated with 3 QTL for feed efficiency traits in chromosome 4, 3 QTL for maintenance traits in chromosomes 4 and 9, and several QTL for milk production in 5 different chromosomes.

\section{Implications}

We have stated previously that ECM and BW are needed in the calculation of $\mathrm{MeP}$ (when using the sniffer method), resulting in artificially induced high correlations between MeP with ECM and BW. Subsequently, for the calculation of MeYp, MeIp, and RMETp under the conventional definition (using $\mathrm{MeP}$ ), it is required to remove the covariance with ECM and BW, to have an independent $\mathrm{CH}_{4}$ trait. One of the main problems in $\mathrm{MeY}$ and $\mathrm{MeI}$ as ratio traits is the strong negative correlation with the denominator trait (DMI and ECM) and an antagonism between the response in the numerator and the denominator. This problem could be solved by

Table 4. SNP significantly associated $(P<0.001)$ with each trait (in parentheses) and number of these SNP validated on the other traits ${ }^{1}$

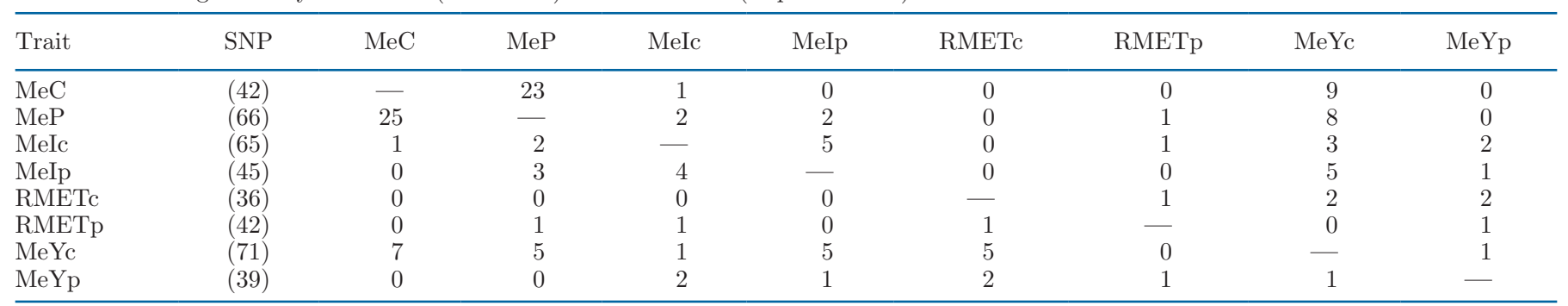

${ }^{1} \mathrm{MeC}=$ methane concentration; $\mathrm{MeP}=$ methane production; MeIc = methane intensity calculated using MeC; MeIp = methane intensity calculated using MeP; RMETc = residual methane on metabolic BW and ECM using MeC; RMETp = residual methane on metabolic BW and ECM using MeP; MeYc = methane yield calculated using MeC; MeYp = methane yield using MeC. Total number of SNP = 38,253. The table should be read per line. 
Table 5. SNP significantly $(P<0.001)$ associated with more than one trait, ${ }^{1}$ chromosome, and base pair position

\begin{tabular}{lccl}
\hline SNP & Chromosome & Position $(\mathrm{bp})$ & Traits associated \\
\hline ARS-BFGL-NGS-93180 & 1 & $138,832,098$ & RMETc, MeYp \\
ARS-BFGL-NGS-24888 & 4 & $3,583,133$ & MeC, MeP \\
Hapmap59221-rs29014908 & 4 & $35,939,871$ & MeIc, MeIp \\
Hapmap44201-BTA-114510 & 4 & $36,842,170$ & MeIc, MeIp \\
Hapmap51046-BTA-75812 & 6 & $61,984,747$ & MeC, MeP \\
Hapmap52436-rs29009653 & 6 & $99,732,094$ & MeIc, MeIp \\
ARS-BFGL-NGS-47330 & 11 & $44,562,022$ & MeC, MeP \\
ARS-BFGL-NGS-12929 & 11 & $64,313,748$ & MeC, MeP \\
Hapmap26463-BTA-159947 & 11 & $92,086,008$ & MeC, MeP \\
Hapmap49571-BTA-32781 & 13 & $47,583,553$ & MeC, MeP \\
BTB-00525367 & 13 & $47,915,618$ & MeC, MeP \\
ARS-BFGL-NGS-70206 & 13 & $48,622,655$ & MeC, MeP \\
BTA-115847-no-rs & 13 & $48,826,815$ & MeC, MeP \\
BTA-37116-nO-rs & 15 & $57,228,610$ & MeC, MeP \\
ARS-BFGL-NGS-32691 & 18 & $34,159,637$ & MeC, MeP \\
ARS-BFGL-NGS-54767 & 18 & $7,605,307$ & MeIc, MeIp \\
UA-IFASA-7562 & 19 & $49,438,164$ & MeC, MeP \\
ARS-BFGL-NGS-103202 & 24 & $61,455,723$ & MeYc, MeYp \\
Hapmap33073-BTA-162864 & 26 & $21,180,893$ & MeC, MeP \\
ARS-BFGL-NGS-2180 & 26 & $24,477,962$ & MeC, MeP \\
ARS-BFGL-NGS-1092 & 26 & $24,531,763$ & MeC, MeP \\
ARS-BFGL-NGS-18194 & 26 & $24,575,207$ & MeC, MeP \\
ARS-BFGL-NGS-81009 & 26 & $26,491,674$ & MeC, MeP \\
Hapmap38478-BTA-20824 & 26 & $28,723,721$ & MeC, MeP \\
Hapmap40449-BTA-61103 & 26 & $31,213,256$ & MeC, MeP \\
Hapmap19519-rs29022379 & 27 & $19,017,466$ & MeIp, MeYc \\
ARS-BFGL-NGS-60192 & 28 & $25,609,489$ & MeC, MeP \\
ARS-BFGL-NGS-24205 & 29 & $25,325,889$ & MeC, MeP \\
\hline
\end{tabular}

${ }^{1} \mathrm{MeP}=$ methane production; $\mathrm{MeC}=$ methane concentration; $\mathrm{MeIc}=$ methane intensity based on $\mathrm{MeC}$; $\mathrm{RMETc}=$ residual methane based on MeC; MeIp = methane intensity based on MeP; RMETp = residual methane based on MeP.

the use of a residual methane trait that is adjusted for ECM, BW, and DMI. However, an underlying problem would be to have ECM or ECM and BW "in" and "out" of these traits (MeIp, RMETp), and how this could affect the genetic variances and therefore their heritabilities. In this study, we explored through GWAS, and genomic correlations, the differences and similarities of $\mathrm{MeC}$ and $\mathrm{MeP}$, and the other trait definitions (MeYc, MeIc, RMETc) using MeC instead MeP. Although our results showed clear similarities between $\mathrm{MeC}$ and $\mathrm{MeP}$ given the genetic correlation $(0.91 \pm 0.07)$ and the number of significant SNP and segments in common between these 2 traits, we cannot conclude based only on the results that those 2 traits are interchangeable. For that, we would need further investigation, taking into account the genetic correlations with other traits such as ECM, BW, and DMI and if possible to study further the correlated responses to selection of these and other traits when including $\mathrm{MeP}$ or $\mathrm{MeC}$ in the breeding goal. Moreover, the other pairs of ratio and residual traits using either $\mathrm{MeP}$ or $\mathrm{MeC}$ consistently showed weaker genetic correlations and practically no similarities in their GWAS results, having fewer SNP and segments in common between them.

\section{Further Research Needs}

Although this is the largest sample size for a GWAS on $\mathrm{CH}_{4}$ traits in dairy cattle (near to 2,000 animals) compared with previous GWAS studies for $\mathrm{CH}_{4}$ traits, this sample size is still considered small compared with GWAS conducted for milk production and other economic traits in Holstein cattle (Jiang et al., 2019; Liu et al., 2020). More $\mathrm{CH}_{4}$ data are necessary to achieve higher power in the GWAS study to detect QTL associated with $\mathrm{CH}_{4}$ traits and be able to calculate the percentage of genetic variance associated with it. According to Gebreyesus et al. (2019), QTL explaining $5 \%$ of genetic variance can be detected with a power of 0.97 with records from 3,000 cows. Ideally, those animals should also have milk production, weight, and feed intake data, not only to calculate some of the composite $\mathrm{CH}_{4}$ traits (as MeY, MeI, and RMET) but also to estimate the genetic correlations between those traits. Though phenotyping of $\mathrm{CH}_{4}$ and DMI are challenging, they are critical to have reliable phenotypes and accurate estimates of parameters that will help us to select for lower $\mathrm{CH}_{4}$ emitting animals in the future. Multitrait GWAS approaches involving $\mathrm{CH}_{4}$, production, and feed 


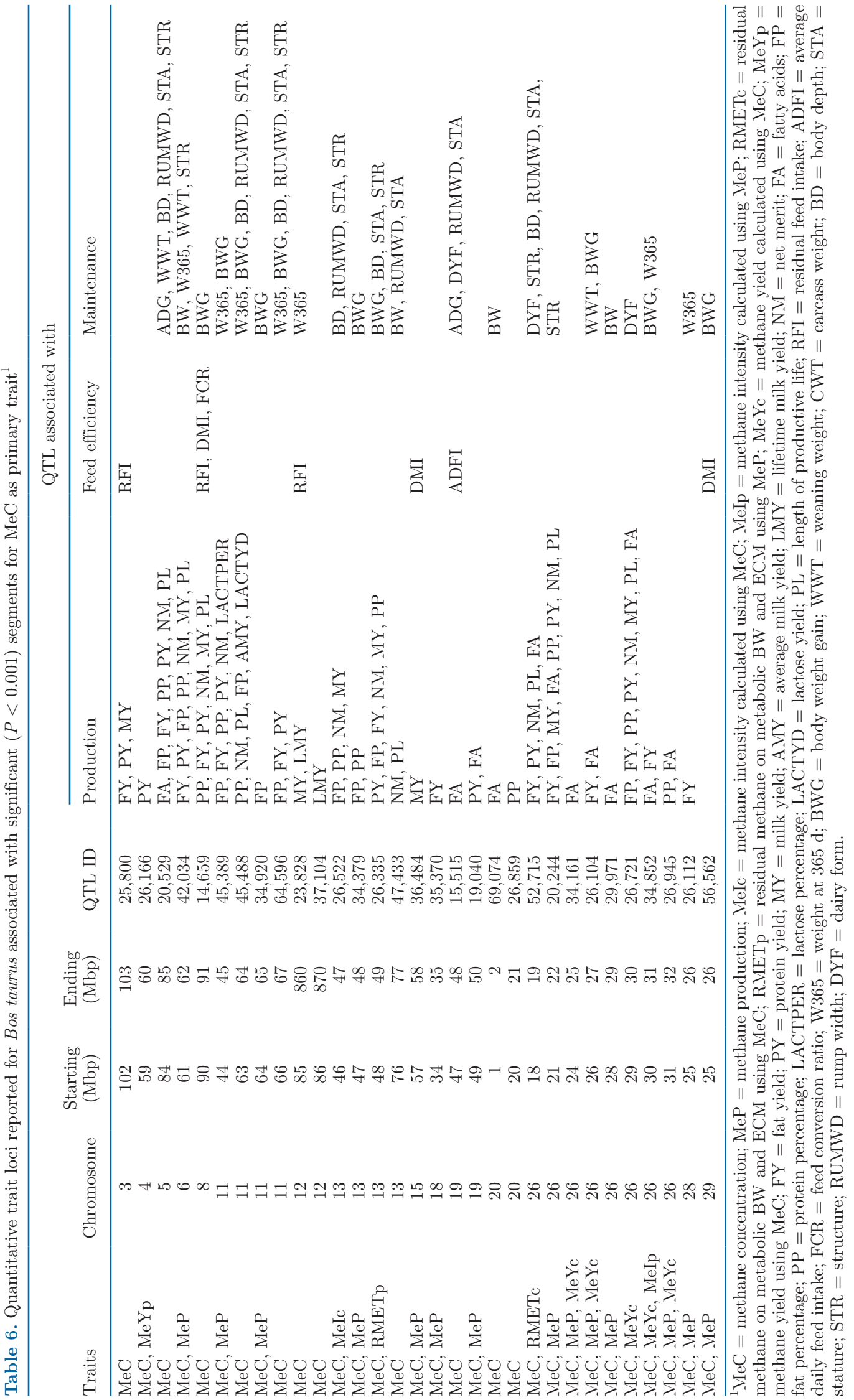


efficiency traits could also be beneficial when investigating the similarities on genetic architecture of the $\mathrm{CH}_{4}$ traits and its correlations with other important traits. We demonstrate unequivocally that the genetic architecture shared by $\mathrm{CH}_{4}$ traits is limited and the trait definition has profound implications for genomic regions detected. Other avenues of future research include Bayesian analyses, which offer more flexibility on the assumed distribution of SNP effects and will be of value as a basis for comparison with the current study. Selecting one $\mathrm{CH}_{4}$ trait for the breeding goal should be accompanied with the proper foundational research about the implications (consequences) of selecting for that trait, such as the correlated response to other economically important traits.

\section{CONCLUSIONS}

Using the sniffer method to measure $\mathrm{CH}_{4}$ has multiple benefits such as the ability to measure many animals with the same equipment during a short period when used in association with AMS at a reduced cost compared with other methods. However, the output trait of the sniffers is $\mathrm{CH}_{4}$ concentration (MeC). To calculate $\mathrm{MeP}, \mathrm{ECM}$ and BW need to be included in the equation, which creates collinearity with milk production and weight that could affect the correlated response of these traits when selecting for lower $\mathrm{CH}_{4}$ emitting animals. The results of this paper show that $\mathrm{MeC}$ and $\mathrm{MeP}$ are genetically more similar than any other pair of traits analyzed, based on their genetic correlation and number of significant SNP and associated genome segments in common. Furthermore, MeC seems to have associations with QTL regions previously reported for milk production, maintenance, and feed efficiency traits.

\section{ACKNOWLEDGMENTS}

This work was funded by a grant from the Danish Milk Levy Fund (Aarhus, Denmark) for the project "Reduceret klimaaftryk på KO-niveau og BEDRIFTSniveau." Per Madsen (Aarhus University) is kindly acknowledged for his help regarding the realization of this study. The authors have not stated any conflicts of interest.

\section{REFERENCES}

Boichard, D., M. Boussaha, A. Capitan, D. Rocha, C. Hoze, M.P. Sanchez, T. Tribout, R. Letaief, P. Croiseau, C. Grohs, W. Li, C. Harland, C. Charlier, M. S. Lund, G. Sahana, M. Georges, S. Barbier, W. Coppieters, S. Fritz, and B. Guldbrandtsen. 2018. Experience from large scale use of the EuroGenomics custom SNP chip in cattle. Page 675 in Proceedings of the World Congress on Ge- netics Applied to Livestock Production, Vol. Molecular Genetics 4. Accessed Oct. 29, 2021. http://www.wcgalp.org/system/files/ proceedings/2018/experience-large-scale-use-eurogenomics-custom -snp-chip-cattle.pdf.

Breider, I. S., E. Wall, P. C. Garnsworthy, and J. E. Pryce. 2018. Genetic relationships between methane emission and milk yield, live weight and dry matter intake. Proceedings of the World Congress on Genetics Applied to Livestock Production, Volume Challenges - Environmental, 134, 2018. WCGALP New Zealand. Accessed Oct. 29, 2021. http://www.wcgalp.org/proceedings/2018/ genetic-relationships-between-methane-emission-and-milk-yield -live-weight-and-dry.

Calderon-Chagoya, R., J. H. Hernandez-Medrano, F. J. Ruiz-Lopez, A. Garcia-Ruiz, V. E. Vega-Murillo, M. Montano-Bermudez, M. E. Arechavaleta-Velasco, E. Gonzalez-Padilla, E. I. Mejia-Melchor, N. Saunders, J. A. Bonilla-Cardenas, P. C. Garnsworthy, and S. I. Roman-Ponce. 2019. Genome-wide association studies for methane production in dairy cattle. Genes (Basel) 10:995. https://doi.org/ $10.3390 /$ genes10120995.

de Haas, Y., M. Pszczola, H. Soyeurt, E. Wall, and J. Lassen. 2017. Invited review: Phenotypes to genetically reduce greenhouse gas emissions in dairying. J. Dairy Sci. 100:855-870. https://doi.org/ 10.3168/jds.2016-11246.

Difford, G. F., J. Lassen, and P. Løvendahl. 2016. Interchangeability between methane measurements in dairy cows assessed by comparing precision and agreement of two non-invasive infrared methods. Comput. Electron. Agric. 124:220-226. https://doi.org/10.1016/j .compag.2016.04.010.

Difford, G. F., P. Løvendahl, R. F. Veerkamp, H. Bovenhuis, M. H. P. W. Visker, J. Lassen, and Y. de Haas. 2020. Can greenhouse gases in breath be used to genetically improve feed efficiency of dairy cows? J. Dairy Sci. 103:2442-2459. https://doi.org/10.3168/ jds.2019-16966.

Donoghue, K. A., T. Bird-Gardiner, P. F. Arthur, R. M. Herd, and R. F. Hegarty. 2016. Genetic and phenotypic variance and covariance components for methane emission and postweaning traits in Angus cattle. J. Anim. Sci. 94:1438-1445. https://doi.org/10.2527/ jas.2015-0065.

FAO, IFAD, UNICEF, WFP, and WHO. 2018. The state of food security and nutrition in the world 2018. Building climate resilience for food security and nutrition. FAO.

Garnsworthy, P. C., J. Craigon, J. H. Hernandez-Medrano, and N. Saunders. 2012. Variation among individual dairy cows in methane measurements made on farm during milking. J. Dairy Sci. 95:3181-3189. https://doi.org/10.3168/jds.2011-4606.

Garnsworthy, P. C., G. F. Difford, M. J. Bell, A. R. Bayat, P. Huhtanen, B. Kuhla, J. Lassen, N. Peiren, M. Pszczola, D. Sorg, M. H. P. W. Visker, and T. Yan. 2019. Comparison of methods to measure methane for use in genetic evaluation of dairy cattle. Animals (Basel) 9:837.

Gebreyesus, G., A. J. Buitenhuis, N. A. Poulsen, M. H. P. W. Visker, Q. Zhang, H. J. F. van Valenberg, D. Sun, and H. Bovenhuis. 2019. Combining multi-population datasets for joint genome-wide association and meta-analyses: The case of bovine milk fat composition traits. J. Dairy Sci. 102:11124-11141. https://doi.org/10.3168/jds .2019-16676.

Hayes, B. J., K. A. Donoghue, C. M. Reich, B. A. Mason, T. BirdGardiner, R. M. Herd, and P. F. Arthur. 2016. Genomic heritabilities and genomic estimated breeding values for methane traits in Angus cattle. J. Anim. Sci. 94:902-908. https://doi.org/10.2527/ jas.2015-0078.

Hu, Z. L., C. A. Park, X. Wu, and J. M. Reecy. 2013. Animal QTLdb: An improved database tool for livestock animal QTL/association data dissemination in the post-genome era. Nucleic Acids Res. 41:D871-D879. https://doi.org/10.1093/nar/gks1150.

Jiang, J., L. Ma, D. Prakapenka, P. M. VanRaden, J. B. Cole, and Y. Da. 2019. A large-scale genome-wide association study in U.S. Holstein cattle. Front. Genet. 10:412. https://doi.org/10.3389/fgene .2019 .00412 .

Khansefid, M., J. E. Pryce, S. Bolormaa, S. P. Miller, Z. Wang, C. Li, and M. E. Goddard. 2014. Estimation of genomic breeding values 
for residual feed intake in a multibreed cattle population. J. Anim. Sci. 92:3270-3283. https://doi.org/10.2527/jas.2014-7375.

Lassen, J., and G. F. Difford. 2020. Genetic and genomic selection as a methane mitigation strategy in dairy cattle. Animal 14:s473-s483. https://doi.org/10.1017/S1751731120001561.

Lassen, J., and P. Løvendahl. 2016. Heritability estimates for enteric methane emissions from Holstein cattle measured using noninvasive methods. J. Dairy Sci. 99:1959-1967. https://doi.org/10 .3168/jds.2015-10012.

Lassen, J., P. Løvendahl, and J. Madsen. 2012. Accuracy of noninvasive breath methane measurements using Fourier transform infrared methods on individual cows. J. Dairy Sci. 95:890-898. https:/ /doi.org/10.3168/jds.2011-4544.

Li, B., B. Berglund, W. F. Fikse, J. Lassen, M. H. Lidauer, P. Mäntysaari, and P. Løvendahl. 2017. Neglect of lactation stage leads to naïve assessment of residual feed intake in dairy cattle. J. Dairy Sci. 100:9076-9084. https://doi.org/10.3168/jds.2017-12775.

Liu, L., J. Zhou, C. J. Chen, J. Zhang, W. Wen, J. Tian, Z. Zhang, and Y. Gu. 2020. GWAS-based identification of new loci for milk yield, fat, and protein in Holstein cattle. Animals (Basel) 10:2048. https://doi.org/10.3390/ani10112048.

Løvendahl, P., G. F. Difford, B. Li, M. G. G. Chagunda, P. Huhtanen, M. H. Lidauer, J. Lassen, and P. Lund. 2018. Selecting for improved feed efficiency and reduced methane emissions in dairy cattle. Animal 12(s2):s336-s349. https://doi.org/10.1017/ S1751731118002276.

Madsen, J., B. S. Bjerg, T. Hvelplund, M. R. Weisbjerg, and P. Lund. 2010. Methane and carbon dioxide ratio in excreted air for quantification of the methane production from ruminants. Livest. Sci. 129:223-227. https://doi.org/10.1016/j.livsci.2010.01.001.

Madsen, P., and J. Jensen. 2014. A user's guide to DMU, version 6 , release 5.0. Cent. Quant. Genet. Genomics Dept. Mol. Biol. Genet. Univ. Aarhus Res Cent., Tjele, Denmark.

Manzanilla-Pech, C. I. V., Y. de Haas, B. J. Hayes, R. F. Veerkamp, M. Khansefid, K. A. Donoghue, P. F. Arthur, and J. E. Pryce. 2016. Genome-side association study of methane emissions in Angus beef cattle with validation in dairy cattle. J. Anim. Sci. 94:4151-4166. https://doi.org/10.2527/jas.2016-0431.

Manzanilla-Pech, C. I. V., D. Gordo, G. F. Difford, P. Løvendahl, and J. Lassen. 2020. Multitrait genomic prediction of methane emissions in Danish Holstein cattle. J. Dairy Sci. 103:9195-9206. https: //doi.org/10.3168/jds.2019-17857.

Mühlbach, S., D. Sorg, F. Rosner, J. Kecman, and H. H. Swalve. 2018. Genetic analyses for $\mathrm{CH}_{4}$ concentrations in the breath of dairy cows measured on-farm with the Laser Methane Detector. Proceedings of the 11th World Congress on Genetics Applied to Livestock Production. WCGALP New Zealand. Accessed Oct. 29, 2021. http://www.wcgalp.org/system/files/proceedings/2018/ genetic-analyses-ch4-concentrations-breath-dairy-cows-measured -farm-laser-methane-detector.pdf.

Pszczola, M., K. Rzewuska, S. Mucha, and T. Strabel. 2017. Heritability of methane emissions from dairy cows over a lactation measured on commercial farms. J. Anim. Sci. 95:4813-4819. https: //doi.org/10.2527/jas2017.1842.
Pszczola, M., T. Strabel, S. Mucha, and E. Sell-Kubiak. 2018. Genome-wide association identifies methane production level relation to genetic control of digestive tract development in dairy cows. Sci. Rep. 8:15164. https://doi.org/10.1038/s41598-018-33327-9.

Purcell, S., B. Neale, K. Todd-Brown, L. Thomas, M. A. R. Ferreira, D. Bender, J. Maller, P. Sklar, P. I. W. De Bakker, M. J. Daly, and P. C. Sham. 2007. PLINK: A tool set for whole-genome association and population-based linkage analyses. Am. J. Hum. Genet 81:559-575. https://doi.org/10.1086/519795.

Richardson, C. M., T. T. T. Nguyen, M. Abdelsayed, P. J. Moate, S. R. O. Williams, T. C. S. Chud, F. S. Schenkel, M. E. Goddard, I. van den Berg, B. G. Cocks, L. C. Marett, W. J. Wales, and J. E. Pryce. 2021. Genetic parameters for methane emissions traits in Australian dairy cows. J. Dairy Sci. 104:539-549. https://doi.org/ $10.3168 /$ jds.2020-18565.

Sargolzaei, M., J. P. Chesnais, and F. S. Schenkel. 2014. A new approach for efficient genotype imputation using information from relatives. BMC Genomics 15:478. https://doi.org/10.1186/1471 $-2164-15-478$.

Sjaunja, L. O., L. Baevre, L. Junkkarinene, J. Pedersen, and J. Setala. 1990. A Nordic proposal for an energy corrected milk formula. 27th Session of the International Commission for Breeding and Productivity of Milk Animals. Paris, France.

Tempelman, R. J., D. Spurlock, M. P. Coffey, R. F. Veerkamp, L. Armentano, K. Weigel, Y. de Haas, C. Staples, E. E. Connor, Y. Lu, and M. VandeHaar. 2015. Heterogeneity in genetic and non-genetic variation and energy sink relationships for residual feed intake across research stations and countries. J. Dairy Sci. 98:2013-2026. https://doi.org/10.3168/jds.2014.8510.

van Engelen, S. 2018. The genetic background of methane emission by dairy cows. PhD thesis. Animal Breeding and Genomics, Wageningen University, Wageningen, the Netherlands. https://doi.org/10 $.18174 / 430631$.

van Engelen, S., H. Bovenhuis, J. Dijkstra, J. A. van Arendonk, and M. H. Visker. 2015. Short communication: Genetic study of methane production predicted from milk fat composition in dairy cows. J. Dairy Sci. 98:8223-8226. https://doi.org/10.3168/jds.2014-8989.

Zetouni, L., M. Kargo, E. Norberg, and J. Lassen. 2018. Genetic correlations between methane production and fertility, health and body type traits in Danish Holstein cows. J. Dairy Sci. 101:2273-2280. https://doi.org/10.3168/jds.2017-13402.

\section{ORCIDS}

C. I. V. Manzanilla-Pech ๑ https://orcid.org/0000-0003-1552-212X

G. F. Difford ๑ https://orcid.org/0000-0002-6792-8722

G. Sahana $\odot$ https://orcid.org/0000-0001-7608-7577

H. Romé $\odot$ https://orcid.org/0000-0002-0714-5961

P. Løvendahl ๑ https://orcid.org/0000-0002-9852-2944

J. Lassen () https://orcid.org/0000-0002-1338-8644 